\title{
Why Should We Bother on Measurement in Wastewater Treatment Operation?
}

\author{
Stig Morling \\ Sweco Environment AB, Stockholm, Sweden \\ Email: stig.morling@sweco.se
}

How to cite this paper: Morling, S. (2016) Why Should We Bother on Measurement in Wastewater Treatment Operation? Journal of Water Resource and Protection, 8, 982-989. http://dx.doi.org/10.4236/jwarp.2016.811079

Received: August 29, 2016

Accepted: October 15, 2016

Published: October 18, 2016

Copyright $\odot 2016$ by author and Scientific Research Publishing Inc. This work is licensed under the Creative Commons Attribution International License (CC BY 4.0).

http://creativecommons.org/licenses/by/4.0/

\begin{abstract}
The question of wastewater treatment and control is reflected from a very specific viewpoint: the low priority given to accurate and useful measurements within wastewater treatment. The matter is discussed from four various perspectives, that may be labelled "Legal understanding"; "Needs for accurate measurement results already in the planning and design stage"; "The measurement problem and human behaviour"; "The understanding of the short term and long term dynamics and changes in pollution and flow loads on a wastewater treatment plant (WWTP)". All these aspects bring about much improved needs for an accurate and frequent measurement scheme both for pollutants and flows entering a WWTP. The conclusion is stated as follows: A far more and well elaborated on-line measurement system at the plants would become a needed tool for improved water environment protection at lower costs.
\end{abstract}

\section{Keywords}

Measurement, Legal Issues, On-Line Instruments, Nitrogen, Sludge Systems, WWTP (Wastewater Treatment Plant)

\section{Introduction}

The need to measure reality has since long been one of the basic conditions for mankind, and thus a fundament in development of civilizations. With respect to water, the ancient Mediterranean area gave early insights into man's conviction that water is an essential condition for life. Both early Greek writers, a number of tellings in the Old Testimony, as well the water distrubution systems in the Roman Empire, provide evidence for the statement, see illustration in Figure 1.

These old Roman constructions may still serve as proofs for an ability to measure and build correctly already in those ancient days. Water also served as metaphors for 


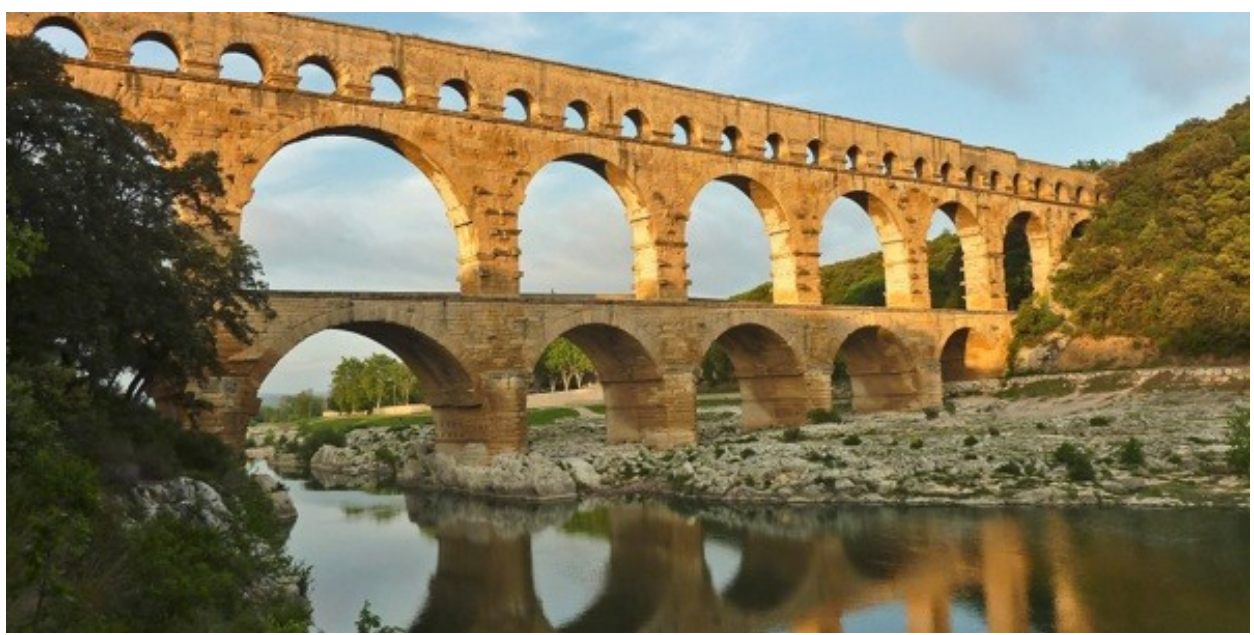

Figure 1. Aqueduct from the Roman Empire.

philosophers and religious leaders. Heraclitus stated: "No man ever steps in the same river twice, for it's not the same river and he's not the same man." The statement reflects an early insight on the problem so well-known for most natural scientists today working within empirical research: To ensure the observations to be valid and trustworthy. Let us go to a much later perspective, but related to the middle Ages through the early Baroque era. Crosby [1] points out that one of the driving factors that developed the Western cultures, was the focus on quantification, or in other words-to measure the reality and facts in our environment. This conviction is one of the fundaments for empirical science that we today use to such a large extent. Another witness of the importance of water in a scientific perspective was given in 1961 by a book called "Water. The Mirror of Science", written by Davis and Day [2]. The findings and fascinating perspectives on water in this book would not have been possible without the use of meticulous measurements and observations. Therefore, it is both surprising and discouraging to find the very low priority that in many cases is given on measurement and a quantified control of modern wastewater treatment (WWTP) facilities, see for instance Grievson [3]. In the following, I will give some examples on such situations, and also highlight some consequences of the lack of adequate measurements. Further, we discussed some causes for this attitude of low priority. Finally, we discussed possible pathways for improvements as well as some quantified motives for a much better process automation, control and evaluation of the real plant performance.

\section{Some Fundamental Considerations on Measurement Results}

In many ways it may be stated that the basis for an efficient process operation of a modern WWTP contains a number of technological perspectives. In this context, however, we concentrate on two important matters:

- An understanding of the possible accuracy of the obtained measured variables;

- The options to use the measured values to operate a WWTP in an improved costsavings model. 
Firstly it may be useful to define the difference between a systematic error and a stochastic error in mea-surement. In Figure 2 the difference is demonstrated.

A systematic error is illustrated in Figure 2(a), where we have low accuracy and high precision. The results of the observations are very close but they all divert from the correct value in a repeated pattern. Now a key question arises: How do we know the correct result? Is it due to inaccurate instruments, a systematic error in the measurement model, or a systematic error in the applied analyses method?

Stochastic errors, with high accuracy and low precision, are illustrated in Figure 2(b). This situation is sometimes solved by calculating and addressing classical statistical parameters such mean value and variance. When long time series are involved it may prove necessary to study more complex parameters, such as autocorrelation, to obtain reliable results.

\section{The Questions}

The question as put forward is the following: "Why should we (at all) bother on measurement and thus the on-line results in wastewater treatment?" The question may be found odd or even peculiar. However, a number of witnesses from real life are (sad) proofs for the relevance in this question. The examples are found within the legal framework, planning, design and operation of wastewater treatment plants. But, perhaps even worse, the legal stipulations on consent values reflect often an almost nonexisting understanding of mathematical statistics! Some concrete cases will be presented in the following. The matter has been discussed in another context by Morling [4]. In order to understand the matter more in detail four different perspectives will be addressed:

- The legal lack of understanding the importance of measurement;

- The lack of understanding of measurements in the planning phase of an environmental investment;

- The measurement problem and human behaviour;

- The needs of understanding the dynamics in especially water treatment.

(a)

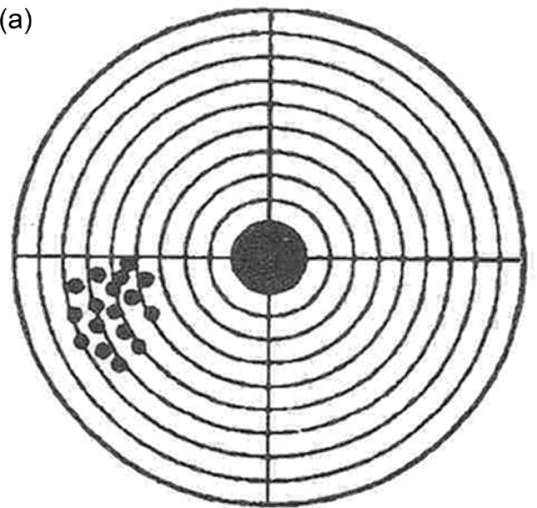

(b)

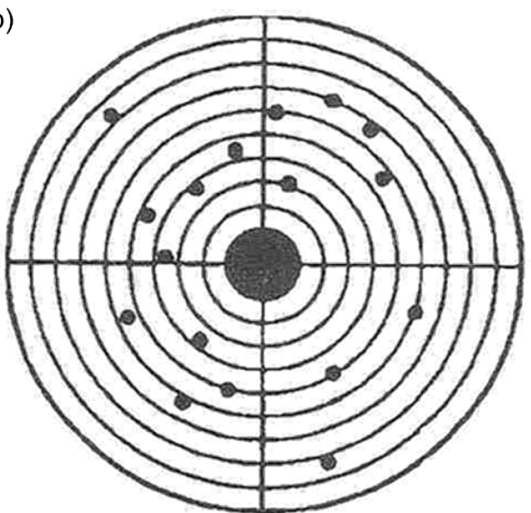

Figure 2. A schematic illustration of the difference between a systematic error (a) and stochastic errors (b). 


\section{Discussion}

\subsection{The Measurement Problem as Reflected in the Legal Framework and Practice}

In this section I will highlight two different points, and start with the adopted European effluent directive (EEC 91/271) [5]. This document has a major importance with respect to the accepted discharge levels of treated wastewater from communities within the European Union. Now, it is easy to find weak points and even erratic perspectives in the document. One of the fundaments for the size estimation is based on what is addressed as a "Person Equivalent" often presented as PE. Now, it is in turned defined as $60 \mathrm{~g} \mathrm{BOD}_{5} / \mathrm{d}$ (in Sweden and some other Nordic countries within Europe the definition is $70 \mathrm{~g} \mathrm{BOD}_{7} / \mathrm{d}$, mainly due to our 5 days a week workdays).

Some critical viewpoints may be addressed to this directive:

- In the first place the directive is already a rather old, this year it "celebrates" its 25 year in operation. As pointed out elsewhere the sustainability within wastewater treatment may be stated to be no longer than around 25 years, see Morling [6];

- The use of BOD as the fundamental pollution may in this perspective become more or less obsolete, as the current knowledge points out other polluting agents to be far more harmful for the water environment. Typical examples are a large number of complex organic compounds (often including chloric ions), phosphorus and nitrogen when it comes to municipal wastewater. In this context it is relevant to highlight the concept "Oxygen Consumption Potential (OCP) that was presented in the 1990s by Professor Halvard Ödegaard, at Norwegian Technical University, Trondheim. The formula is as follows: The use of BOD as the fundamental pollution may in this perspective become more or less obsolete, as the current knowledge points out other polluting agents to be far more harmful for the water environment. Typical examples are a large number of complex organic compounds (often including chloric ions), phosphorus and nitrogen when it comes to municipal wastewater. In this context it is relevant to highlight the concept "Oxygen Consumption Potential (OCP) that was presented in the 1990s by Professor Halvard Ödegaard, at Norwegian Technical University, Trondheim. The formula is as follows:

$\mathrm{OCP}=a^{\prime} * \mathrm{BOD}+4.6 * \mathrm{~N}_{\mathrm{ox}, 1}+14 * \mathrm{~N}_{\mathrm{ox}, 2}+100 * \mathrm{P}$;

where

$a^{\prime} \star \mathrm{BOD}=$ the direct oxygen consumption in a receiving water body, by convention the factor $\mathrm{a}^{\prime}$ is often set as 1.0 ;

$4.6 * \mathrm{~N}_{\mathrm{ox}, 1}=$ the equivalent oxygen consumption when nitrogen compounds are transformed into nitrate $\left(\mathrm{NO}_{3}\right)$;

$14 * \mathrm{~N}_{\mathrm{ox}, 2}=$ the equivalent oxygen consumption when nitrogen compounds are causing algae growth and decomposition in the receiving water body;

$100 * \mathrm{P}=$ the equivalent oxygen consumption when phosphorus compounds are causing algae growth and decomposition in the receiving water body.

This model has been addressed and used in water environmental projects both in the US theatre, see Jeyanayagam and Sandino [7] and for projects in the Baltic rim, 
see Nystén [8].

A third decisive factor is that the $\mathrm{BOD}$ is far from a measurement (practical) tool for loading assessment or discharge control. This statement is linked to two circumstances: 1 . The inaccuracy in the analysis ( $+/-20 \%$ to $30 \%$ in the single observation). This in turn means that we need a number of independent BOD-analysis to get trustworthy result from the sampling control; 2 .The by convention extended time to get the results from the laboratory analysis, theoretically minimum 5 (or 7) days, in practice a far longer response period. In this perspective it is also relevant to underline that COD and, lately, TOC (Total Organic Carbon) are by and by replacing the BOD as control variables within wastewater management and control.

- The actual measurement methods on crude wastewater would in the first place be the ones that respond accurately and quickly, thus enabling an improved plant operation. This in turn would in many ways promote on-line measurements.

\subsection{The Measurement Problem as in the Planning and Design of a Modern WWTP}

A typical planning and design work is normally based on a 15 to 25 year design horizon. This in turn calls for a thorough consideration during the design work. In the first place it is important to underline that the applied design models today are sophisticated, especially when it us applied on modern concepts of activated sludge system. These mathematical calculations are normally based on computerized models. The clear benefit that these models bring about is the possibility to test different design configurations at theoretically different loads and operation conditions. However, all these achievements may become more or less "obsolete", if no critical follow up is done during the real operation phase. The key element in such a follow up is a comprehensive, well elaborated and maintained on-line measurement system. The first point is how to handle the (necessary) load variation over time. This matter must be addressed already during the detailed design phase. A careful selection of on-line instruments combined with a flexible computerized control system is a necessity. The instrumentation and active use of the thus obtained information may to a large extent contribute to an improved operation in terms of lower operation costs at lower discharge levels of the stipulated pollutant variables. The measurement problem will now be further discussed in additional perspectives.

\subsection{The Measurement Problem and Human Behaviour}

A successful operation of a WWTP is still heavily dependent on the skill, diligence, and dedication of the operators at site. This statement should not be overlooked, even though the modern WWTP has become more and more automated There may be a substantial risk that operators not properly trained-or with an unfavourable attitude-may heavily influence measurement results and thus the operational results. This, of course, is a management problem. But, and this is important, it is also the responsibility of management to listen carefully to the observations and opinions of the 
operators, and avoid the attitude that "the manager is always right and always knows best". It is thus important to create an atmosphere of openness and cooperation in order to avoid situations, such as those elaborated below.

At a WWTP sized for 15,000 inhabitants the operators complained after a one and a half year's operation that the on-line oxygen meters did not perform. A portable oxygen meter was brought to the site. This meter was of course calibrated immediately prior to use. It was placed side by side with the installed oxygen meter. The latter showed a free oxygen level in the reactor $=0.0 \mathrm{mg} \mathrm{O}_{2} / \mathrm{l}$, while the portable one showed $3.0 \mathrm{mg} \mathrm{O}_{2} / \mathrm{l}$. So we asked the operator: "When did you last took up the on-line meter for maintenance and calibration?" The answer was: "The man who installed the meter said that this unit does not need any maintenance!" In other words, this statement on maintenace-free devices is either an evidence of ignorance or a very false pretention!

A second example from a large WWTP in Scandinavia gives us an example of an internal authoritarian attitude. The operator that is entrusted the operation and control of all on-line instruments observed that there was a consistent difference between the on-line recording of the suspended solids concentration in the aerated reactors and the results that were presented from the quality accredited laboratory. The difference varied often significantly, and by large with higher values found at the direct on-line measurement results. In the first place the operator's observations were neglected. However, thanks to a combination of curiosity and stubborn attitude from the operator, he took out own samples and handled them in the manner as the ones sent to laboratory. All of a sudden he found the same results in both samples taken and handled more or less identically in the laboratory procedure. The probable hypothesis that may explain the results could be the following: A SS sample from an aeration basin is in fact a "living material". The organics will continue to change as time goes by due to microbiological activity. The matter would be possible to reveal if also the VSS-part was analyzed directly at the sampling time and after the "normal" handling time has passed-from sampling until the actual analysis is performed at the laboratory.

\subsection{The Measurement Problem as Reflecting and Understanding the Dynamics in Especially Water Treatment}

As already pointed out a municipal WWTP will have to treat substantial variations with respect to both flows and loads during its operation lifetime. Now the situation may be even more crucial. Even during such a short period as one quarter of a year the operation conditions may vary substantially. The matter is illustrated in Figure 3. The example is taken from a large WWTP in southern Poland serving both the city of Nowy Targ and the industries within the city border. The figure illustrates the ratio COD/total $\mathrm{N}$ in untreated wastewater entering the plant, see Morling [9]. The ratio is given in relation

to the actually calculated nitrification rate during the coldest time of the year-January through March during one single year (2005). As found in the figure the crude wastewater had anything of a stable relation between the organic pollution (expressed as COD) and total Nitrogen. The analysis activity and process follow up at this specific 


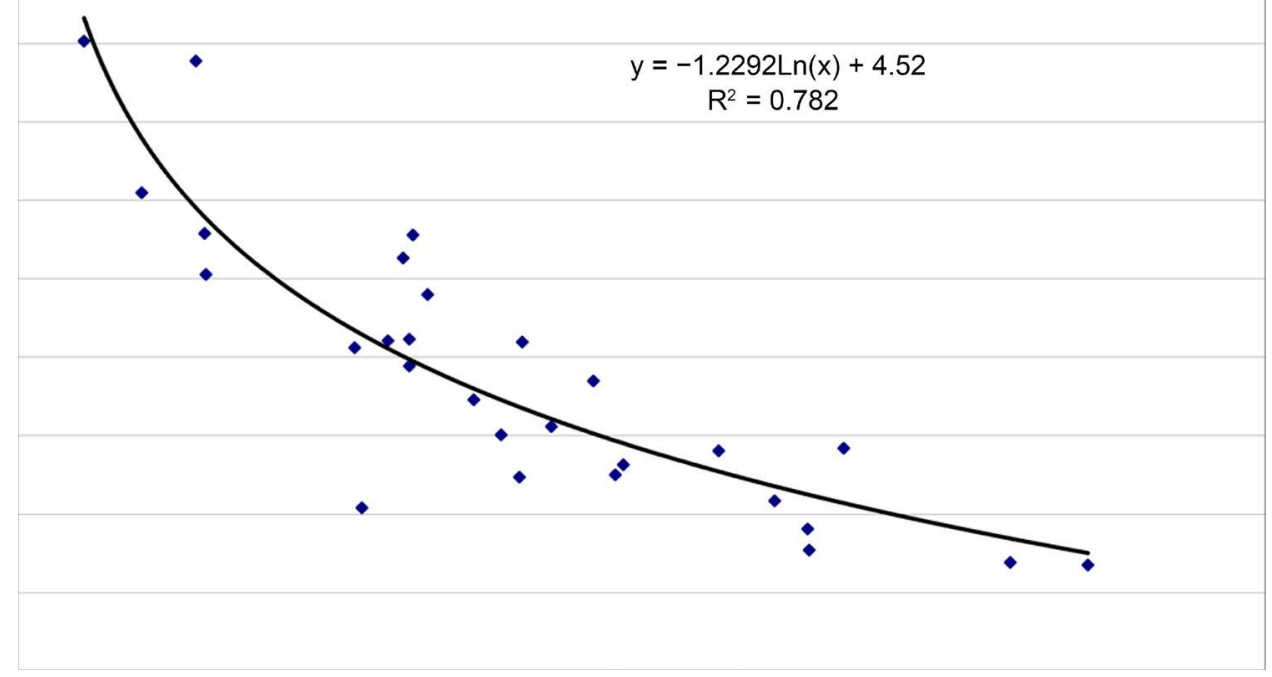

Figure 3. Nowy Targ SBR plant COD/N ratio and specific nitrification rate, 1st quarter 2005, semi-logarithm-function (29 observations)

plant has been extensive, with flow proportional samplings taken out every third day as a normal procedure at the plant. Thus the results may provide a valid illustration of the short time variations that most WWTPs are exposed to. A second point may be that these substantial changes of pollution ratios, even during a short time call for a comprehensive and well elaborated measurement philosophy. This would then include the installation and use of on-line measurements that allows for an active process operation control.

\section{Conclusions}

The measurement within wastewater treatment is being treated with far from acceptable in different aspects. This paper has focused on four different perspectives. Other additional perspectives may be added by others. However, one fundamental aspect may be driven back to the very low actual common interest in water and especially waste water. I started this paper with a reference to the booklet title: "Water. The Mirror of Science". As an ironic metaphor we may state that Water is a Mirror for fools, when we look upon the lack of interest and scientific reflection from the official decision takers. Even more we may state a very low value is given the importance of one of our most precious chemicals in life, water.

Another conclusion that may be derived is the following: It would be time to replace the use of BOD as a significant water control pollution variable in favor of more relevant variables, such as nitrogen and phosphorus. Both these nutrients are possible to measure on-line, and thus serving as direct variables for process control and process operation.

Now, a final conclusion that would be evident is the following: An on-line measurement system within a WWTP would allow for an efficient savings of both energy input and chemicals for the benefit of an improved environment, as the overall "environ- 
mental footprint" as a result will decrease.

\section{Acknowledgements}

A number of friends and scholars have taken their time to go through this paper, and also taken their time for fruitful discussions of this important matter. Mr. Pär Håkan Bergström, who more or less highlighted the matter by referring to the current situation at some plants. Further Mr. Peter Lindström at Stockholm Water Company, who described practical matters related to the measurement problems. Mr. Per-Lennart Karlsson who has supported with pedagogic viewpoints and corrected statistical questions in the paper. Finally my colleague, Mr. Guy Taylor, who has scrutinized and corrected the linguistics in the paper.

\section{References}

[1] Crosby, A.W. (1997) The Measure of Reality: Quantification and Western Society, 12501600. Cambridge: Cambridge University Press.

[2] Davis, K.S. and Day, J.A. (1961) Water: The Mirror of Science. Science Study Series, S18, Mass Market Paperback.

[3] Grievson, O. (2016) Weekly Update from Water Industry Process Automation \& Control, Oliver Is a Group Manager-Water Industry Process Automation \& Control.

[4] Morling, S. (2014) Problems in Water Environmental Control-Sense and Nonsense in Measurement of Water Protection. Journal of Water Resource and Protection, 6, 13811389. http://dx.doi.org/10.4236/jwarp.2014.615127

[5] EU Urban Wastewater Treatment Directive 91/271 EEC.

[6] Morling, S. (2014) How Sustainable Is Our Wastewater Treatment? Journal of Water Resource and Protection, 6, 1060-1065. http://dx.doi.org/10.4236/jwarp.2014.612101

[7] Jeyanayagam, S. and Sandino, J. (2011) $\mathrm{CH}_{2}$ MHILL: General Operation Considerations in Nutrient and Wet Weather Flow Management for Wastewater Treatment Facilities. Presentation given at Ohio WEA Plant Operations Workshop, September 282011.

[8] Nystén, A. (2014) Nefco: Assessment of Regional Nutrient Pollution Load and Identification of Priority Investment Projects to Reduce Nutrient Pollution from Belarus to the Baltic Sea. EUSBSR Flagship Project BSAP Fund.

[9] Morling, S. (2008) Nitrogen Removal Efficiency and Nitrification Rates at the Sequencing Batch Reactor in Nowy Targ, Poland. Vatten, 2, 121-128. 
Submit or recommend next manuscript to SCIRP and we will provide best service for you:

Accepting pre-submission inquiries through Email, Facebook, LinkedIn, Twitter, etc. A wide selection of journals (inclusive of 9 subjects, more than 200 journals)

Providing 24-hour high-quality service

User-friendly online submission system

Fair and swift peer-review system

Efficient typesetting and proofreading procedure

Display of the result of downloads and visits, as well as the number of cited articles

Maximum dissemination of your research work

Submit your manuscript at: http://papersubmission.scirp.org/

Or contact jwarp@scirp.org 